\title{
Enhancing Nurses`Competency on Adherence to Bundle Prevention Protocol for Ventilator Associated Pneumonia
}

1Basma M. Khalil, 2Howyda A. Mohamed, 3Susan M. Abdelghany, 4Mayar H. Elsersy

Departments of Medical - Surgical, Faculty of Nursing, 4 Anesthesias and Intensive Care, Faculty of Medicine, Ain Shams University

\begin{abstract}
:
Aim: This study aimed to evaluate the effect of enhancing nurses ' competency on bundle prevention protocol for ventilator associated pneumonia(VAP). Subjects and Method : A quasi-experimental design was utilized for the conduction of this study in the following Critical Care Units (Neuro- Medicine, Intensive Care Unit (ICU), Coronary Care Unit (CCU) and Emergency) of Medical Hospital affiliated to Ain Shams University and El Sayed - Galal Hospitals . Sample: A purposive sample was composed of 70 critical care nurses and 40 critically ill patients from the above mentioned settings. Tools of data collection : 1) Self-administered questionnaire (pre / posttests) to assess the studied nurses' knowledge as regards Ventilator associated pneumonia (VAP) prevention bundle . 2) An observation checklist (pre / posttests) to evaluate studied nurses ' practices in relation to care of patients with Ventilator Associated Pneumonia (VAP) and bundle prevention protocol . 3) Hamilton Anxiety Rating Scale (pre / posttests) to assess studied nurses`anxiety level. 4) Nurses ' opinnionair sheet (pretest) to identify their opinions regarding competency obstacles. 5) Patients` condition assessment sheet (posttests). Results: More than half of the studied nurses had diploma nursing with less than five years of experience. In addition, there were unsatisfactory level of nurses ' knowledge, practices , added to elevated anxiety level in pretest. As regards the studied patients, less than half of them had the age of $(20-<35 \mathrm{yrs})$. Conclusion : On light of the current study results, it can be concluded that , enhancing nurses' competency (knowledge and practices) through educational guidelines was helpful on adherence to bundle prevention protocol for ventilator associated pneumonia (VAP ). Recommendations: Further studies should be carried out on a large number of critical care nurses with evidence of results and
\end{abstract} generalization .

Key Words: Ventilator Associated Pneumonia - Adherence to Bundle Prevention Protocol - Enhancing Nurses`Competency.

\section{Introduction:}

Today ventilator-associated pneumonia (VAP) is a potentially preventable iatrogenic illness that may develop following mechanical ventilation and a major health concern in hospitals. It represent a type of lung infection that affects critically ill patients and developed 48 hours or longer post mechanical ventilation. Moreover, the leading cause of nosocomial infection, increased morbidity, longer hospital stay, increased health care costs, and higher mortality rates (Marini et al., 2016 \& Kollef et al., 2014). It occurs because the obtunded endotracheally intubated patient is at risk of inoculation of lower respiratory tract with microorganisms. Staphylococcus aurous is the most common pathogen associated with VAP and the leading cause of death. VAP can be of two types: Early onset which develops within 5 days of mechanical ventilation and late onset which develops 5 days or more after mechanical ventilation. The diagnosis usually requires a new infiltrate on chest $\mathrm{x}$-ray plus temperature $>38^{\circ} \mathrm{C}$ or $<36{ }^{\circ} \mathrm{C}$, white blood cell count $>12 \times 109 / \mathrm{ml}$, purulent secretions from the airways and reduction in gas exchange (Russell et al., 2016 \& Michetti et al. ,2014).

The incidence of VAP increases with duration of mechanical ventilation. Estimated rates are 3\% per day for the first 5 days, $2 \%$ per day for days $6-10$ and $1 \%$ per day after day 10. In New York, the rates of adults VAP might count $27 \%$ of all infections in CCU . The National Healthcare Safety Net- work reported 2.1 to 10 incidents per 1,000 ventilator days. Research evidence shows that VAP incidence reaches around $32 \%$ in Athens. In Egypt, it is a tremendous problem with continuous elevation in its incidence . This observation was supported through studies concerned with incidence of VAP in two universities; Alexandria (four studies) and Mansoura (one study). Incidence of VAP ranged from $16 \%$ to $75 \%$ with the lowest ratio in Alexandria ( Burja et al., 2017 , Ismail \& Zahran , 2015 \& Fathy et al. , 2013).

Risk factors of VAP were classified as patient related risk factors: chronic diseases, immunosuppressed drugs, low consciousness, thoracic / abdominal surgery, previous antibiotic and infection. Access , treatment and personnel related risk factors : placement of ryle, enteral feeding, gastric over distension, stress ulcer treatment, supine position, nasal intubation, instillation of normal saline, shortage of staff, poor hand washing protocol, and lack of training in VAP prevention ( Wong et al., 2016 \& Safdar et al. , 2015).

Prevention of VAP include: minimizing occurrence of micro-aspiration, colonization of upper airway and GI tract with potentially pathogenic organisms or contamination of ventilator/ respiratory equipment. Bundle care of VAP is defined as a series of steps related to ventilator care that should be implemented together to improve clinical outcomes and prevention of VAP. Recent evidence has challenged current widespread practice so; most recent advances in interventions for VAP prevention are needed (Marini \& Khan, 2016 and Kalanuria et al. , 2014).

According to the Institute for Healthcare Improvement (IHI) five components of ventilator associated 
pneumonia bundle are: Hand washing and use of gloves. Elevation of head of bed to 30- 45 degrees. Suctioning of sub-glottic secretions. Daily sedation vacation, assessment of readiness to extubation and implementation of comprehensive oral hygiene program. Peptic ulcer and deep vein thrombosis prophylaxis (Larrow, 2016 \& Zack et al., 2012).

Nurses play an important role in identification of risk factors and pathophysiology of ventilator associated pneumonia, mechanical ventilation, duration of ventilation, prevention of VAP by using a bundle care. Prevention of VAP becomes the focus for both nurses and respiratory therapists working with ventilated patients (Dewit et al., 2016 and Hinkle \& Cheever, 2014).

\section{Significance of the study:}

VAP is the most commonly reported health care acquired infection in $\mathrm{CCU}$ and the hospital mortality rate of ventilator patients who develop VAP is $46 \%$, compared to $32 \%$ do not develop . Moreover, it increases severity of illness as it elevates oxygen demands, sputum production, and produces alveolar collapse leading to impaired gas exchange. Patient might experience discomfort, agitation, delirium, immobility, and/or risk for impaired skin integrity, hemodynamic instability, as well as an increased stress response and malnutrition (Larrow, 2016 \& Mori et al. , 2016).

Critical care nurse has an important and crucial role in developing the best practice standards in an attempt to prevent VAP. Nurses' education and reinforcement is considered as the cornerstone and the first step in preventing VAP. Therefore, the present study was designed to enhance nurses ' competency on bundle prevention protocol for ventilator associated pneumonia (VAP) .

\section{Aim of the Study:}

This study aimed to evaluate the effect of enhancing nurses ' competency on bundle prevention protocol for ventilator associated pneumonia (VAP ) This aim was achieved as follows :

- Assess studied nurses' knowledge, practices and anxiety level as regards bundle prevention protocol for VAP.

- Identify the obstacles affecting on studied nurses' competency (physical, psychological, social and administrative) added to the suggested solutions.

- Develop and implement the educational guidelines for the studied nurses about bundle prevention protocol for VAP.

\section{Evaluate its effect on :}

- Nurses`knowledge, practices and anxiety level.

- Incidence of VAP among studied patients post guidelines

\section{Hypothesis:}

It was hypothesized that, the educational guidelines had a positive effect on nurses` competency (knowledge and practices) as regards implementation of bundle prevention protocol for VAP among mechanical ventilated patients

\section{Subjects and Method: \\ Operational definitions:} practices

Competency: means nurses' knowledge and

Educational guidelines: means theoretical and practical sessions

Adherence: means implementing bundle prevention protocol of VAP for full initially intended duration.

\section{Research design:}

A quasi-experimental design was utilized to conduct this study

\section{Setting:}

This study was conducted in: Medical Hospital affiliated to Ain Shams University hospitals and El Sayed Galal Hospital in the following Critical Care Units (Neuro- Medicine, ICU, CCU and Emergency) .

\section{Subjects:}

A purposive sample was composed of 70 nurses with different ages, education and experiences. In addition, 40 critically ill patients with different diagnosis they were taken as follows:

\section{Ain Shams University Hospitals \\ Medical Hospital ( 40 nurses, 20 patients ) :}

10 nurses and 5 patients from each unit (Neuro- Medicine, ICU, CCU and Emergency).

El Sayed - Galal Hospital :

Medical Hospital (30 nurses, 20 patients ):

7 nurses and 5 patients from each unit ( NeuroMedicine (7), ICU (7), CCU (7) and Emergency (9))

\section{Inclusion criteria for :}

- Nurses

- Nurses willing to participate in the study.

- Nurses working in critical care units.

- Nurses`experience not less than one year.

- Patients

- Patients on mechanical ventilator

- Patients without VAP

\section{Tools of data collection:}

Self-administered questionnaire (pre/post tests) . It was designed by the researchers in light of the relevant and related literatures and written in simple Arabic language . Data obtained were related to: 
Demographic characteristics of the studied nurses which included (age, sex, qualifications, years of experience and previous training )

\section{Nurses` knowledge assessment sheet about :}

Ventilator associated pneumonia (VAP) prevention bundle : Definition of VAP, diagnostic measures, management, characteristics and complications . Moreover, definition of VAP prevention bundle and its components.

Risk factors of VAP: (Patients : Disturbed level of consciousness, malnutrition and aspiration of contaminated secretion. Nurses : Suctioning, frequently, utilizing clean gloves for tracheal suction, performing ineffective hand hygiene, rubbing with Alcohol when visible secretions and washing hands when there is no visible secretions . Doctors: Giving multiple antibiotics, broad spectrum and intubating patients nasally).

\section{Scoring system:}

Responses of the studied nurses were scored as (1) for correct answer and (zero) for incorrect answer. The total score was categorized into either satisfactory level (from $70 \%$ and more) or unsatisfactory level (less than $70 \%$ ).

\section{An observation checklist (pre / posttests):}

It was adopted from ( Lewis et al. , 2014 , Hinkle \& Cheever, 2014 and Dewit et al. ,2016 ), developed and filled by the researchers to evaluate studied nurses ' practices regarding :

Care of patients with ventilator associated pneumonia (VAP) : Infection control measures, sterilized ambo bag / neubelizer device, postural drainage, percussion and vibration technique, patient's position changed frequently, endotracheal tube care, nasogastric tube feeding/care and ventilator care .

Nurses' practices regarding bundle prevention protocol of VAP: Patients position (Keep head position in 30 - 45 degree). Infection control measures (Hands washing pre/post patient contact and in between - Change gloves between patients - Sterile ambu bag and disinfect it before use). Ventilator care (Drain and discard periodically any condensate collected in mechanical ventilator tube - Humidify respiratory circuit using humidity and heat exchange filter - Replace humidifiers and ventilator circuit regularly - Change heat moisture exchanger when becomes visibly). Endo tracheal suction care (Adequate pressure in endotracheal tube cuff - Wear clean gloves with closed / open suction - Use sterile equipment / technique with tracheal suction Replacement of suction solution and tubes - Use saline/ distilled water prior to suction - Continuous aspiration of sub glottis secretions if ventilator more than 48 hours). Oral care (Oral hygiene with antiseptic solution - Topical antimicrobial agents for oral decontamination regularly). Peptic ulcer prophylaxis (Checking gastric residual volume every 4-6 hours Administer enteral feeding - Routine acidification of gastric feeding). Extubation and weaning trials (Sedation interruption - Daily readiness assessments to wean and extubate). DVT prophylaxis (Using antiembolic stockings or sequential compression).

\section{Scoring system:}

A correct practice was scored as (1), while the incorrect (zero). It was scored into either inadequately done (less than $70 \%)$ or adequately done $(70 \%$ and more). The total score was categorized as satisfactory $=70-100$, or unsatisfactory $=$ less than 70 .

\section{Hamilton Anxiety Rating Scale (pre / posttests):}

It was developed by Hamilton (1959) and modified by the researchers. This scale formed of thirteen variables: anxious mood, tension, insomnia, cognitive changes, depression, somatic (sensory), cardiovascular, respiration, gastrointestinal, genitourinary, autonomic symptoms, somatic (muscular) and the behavior at the interview. Testing reliability of the scale items using alpha cronbach test $=0.83$.

\section{Scoring system:}

Answers were (0-3) scores and total score ranged from $0-39$, the following categorization were adapted: no anxiety (zero), mild anxiety (0 - less than 23), moderate anxiety (23 - less than 29) and severe anxiety (29 - 39).

Nurses`opinnionair sheet (pretest): It was designed by the researchers to identify their opinions regarding the competency obstacles (physical, psychological, administrative and social obstacles) in care of studied patients, added to the suggested solutions .

Patients` condition assessment sheet (posttests). It was composed of the following:

- Characteristics of the studied patients as regards age , length of intubation / ventilation (days) and length of stay in ICU (days) .

- Patients`assessment as regards the incidence of ventilator associated pneumonia among studied patients

\section{Content validity:}

It was assured by a group of experts from $\mathrm{CCU}$ and Medical- Surgical Nursing. . Their opinions were collected as regards to tools format layout, consistency and scoring system. Tools' contents were tested regarding to the knowledge accuracy, relevance and competence.

\section{Ethical considerations:}

In the planning stage approval was obtained from directors of the above mentioned settings. All nurses were informed about the study and their rights according to medical research ethics that they were free to decide whether or not they would participate in the study. Then a written informed consent was obtained from each nurse who agreed to participate in the study.

\section{Pilot study:}

A pilot trial was carried out on $10 \%$ of the total study sample to test the clarity and practicability of the tools, in addition to subjects and settings. Pilot subjects were 
later included in the study as there were no radical modifications in the study tools.

\section{Procedure:}

- Study purpose was simply explained to the nurses who agreed to participate in the study prior to any data collection .

- $\quad$ The current study was started and completed within 6 months.

- Researchers started to collect data from the studied nurses in the critical care units of the above mentioned setting using the pre constructed tools .

- Data were collected by the researchers 2 days/week, at morning / afternoon shift, added to through follow - up visit.

- The guidelines were designed based on analysis of the actual educational nurses' needs in pretest .

- Guidelines' content was written in simple Arabic language and consistent with the related literature, as well as met nurses' needs and their level of understanding.

- Educational guidelines were presented in theoretical and practical sessions. Nurses were divided into small groups including 5-6 and repeated sessions included all nurses, each group obtained 4 sessions ( 2 theories and 2 practices). Moreover, each nurse was guided by simple written instructions and then orientation about objectives and outline was done.

- Theoretical part was implemented through lectures and group discussions, using data show and poster as a media. It was taken in 4 hours for 2 sessions (one session weakly for 2 hours) which were covered on 2 weeks ) and cover the following items regarding VAP prevention bundle : Definition of VAP, diagnostic measures , management, characteristics, complications , definition of VAP prevention bundle and its components . In addition, risk factors of VAP (Patients, nurses and doctors).
- Practical part was implemented through demonstration, re- demonstration and video. It was taken in 9 hours for 3 sessions (one session weakly for 3 hours ) and covers the following items . First and second sessions regarding care of patients with VAP: Infection control measures , sterilized equipment's and devices, postural drainage and percussion technique, ventilator care, patients' position, endotracheal and nasogastric tube care / feeding) . Third session regarding bundle prevention protocol of VAP was included patients' position, infection control measures, ventilator care measures, endo tracheal suction care, oral care , peptic ulcer prophylaxis, extubation/weaning trials and DVT prophylaxis

- Nurses were informed to be in contact with the researchers by telephone for any guidance.

- Nurses were assessed in groups that entail 5-6 according to their readiness.

- Ealuation of the guidelines' effect on studied nurses and patients as regards :

- Nurses' knowledge, practices and anxiety level by using pretest (Before guidelines sessions), post - test (immediately after guidelines) and follow- up test (After 3 months later) by using the same tools.

- Nurses 'opinions regarding the competency obstacles in care of studied patients by using the pretest.

- Patients'incidence of VAP were assessed pre guidelines, one month post guidelines and after two months later using the same tools.

\section{Statistical Design:}

The data collected were organized, sorted, tabulated and analyzed using Statistical Package for Social Sciences (SPSS). They were presented in tables and charts using numbers, percentages, means, standard deviations and $\mathrm{t}-$ test . Level of significance was threshold at 0.05

\section{Results:}

Table (1): Characteristics of the studied nurses $(n=70)$

\begin{tabular}{|c|c|c|c|c|}
\hline \multirow{2}{*}{ Items } & \multicolumn{2}{|c|}{ Ain Shams Hospital Nurses $(n=40)$} & \multicolumn{2}{|c|}{ El- Sayed Galal Hospital Nurses $(n=30)$} \\
\hline & No & $\%$ & No & $\%$ \\
\hline \multicolumn{5}{|l|}{ Age } \\
\hline $25-<35$ & 24 & 60.0 & 19 & 63.3 \\
\hline $35-<45$ & 12 & 30.0 & 8 & 26.7 \\
\hline 45 and more & 4 & 10.0 & 3 & 10.0 \\
\hline $\mathrm{X} \% \pm \mathrm{SD}$ & \multicolumn{2}{|c|}{$33.3 \pm 25.2$} & \multicolumn{2}{|c|}{$33.3 \pm 27.3$} \\
\hline \multicolumn{5}{|l|}{ Gender } \\
\hline Female & 33 & 82.5 & 25 & 83.3 \\
\hline Male & 7 & 17.5 & 5 & 16.7 \\
\hline
\end{tabular}


Minia Scientific Nursing Journal (Print) (ISSN 2537-012X) Vol. (3) No. (1) July 2018

\begin{tabular}{|c|c|c|c|c|}
\hline \multirow{2}{*}{ Items } & \multicolumn{2}{|c|}{ Ain Shams Hospital Nurses $(n=40)$} & \multicolumn{2}{|c|}{ El- Sayed Galal Hospital Nurses $(\mathrm{n}=30)$} \\
\hline & No & $\%$ & No & $\%$ \\
\hline \multicolumn{5}{|l|}{ Qualification } \\
\hline Diploma of nursing & 21 & 52.5 & 16 & 53.3 \\
\hline Bachelor & 13 & 32.5 & 10 & 33.3 \\
\hline Postgraduate & 6 & 15.0 & 4 & 13.4 \\
\hline \multicolumn{5}{|l|}{ Years of experience } \\
\hline$<5 \mathrm{yrs}$ & 27 & 67.5 & 20 & 66.7 \\
\hline 5yrs. \& more & 13 & 32.5 & 10 & 33.3 \\
\hline Previous training & 15 & 37.5 & 11 & 36.7 \\
\hline
\end{tabular}

Table (1): Reveals studied nurses' characteristics. Results clarified that mean age of nurses at Ain Shams and El Sayed Galal Hospitals were ( $33.3 \pm 25.2$ \& $33.3 \pm 27.3$ respectively). As regards their gender, majority of them were female $(82.5 \& 83.3$ respectively $)$. Concerning qualifications, more than half of them had diploma nursing (52.5 \& 53.3 respectively ). Regarding years of experience, nearly two thirds of them were with less than five years of experience $(67.5 \& 66.7$ respectively ). In relation to previous training, more than one third of them had training ( $37.5 \& 36.7$ respectively ).

Table (2): Characteristics of the studied patients in CCU (n=40)

\begin{tabular}{|c|c|c|}
\hline Items & $\begin{array}{l}\text { Ain Shams } \\
\text { patients }(n=20) \%\end{array}$ & $\begin{array}{l}\text { El Sayed Galal patients } \\
(\mathrm{n}=20) \%\end{array}$ \\
\hline $20-<35$ & 46.0 & 40.0 \\
\hline $35 \&$ more & 54.0 & 60.0 \\
\hline $\begin{array}{l}\text { Length of intubation and ventilation /days } \\
\text { Min -Max }\end{array}$ & $4-14$ & $3-15$ \\
\hline $\begin{array}{l}\text { Length of stay /days } \\
\text { Min-Max }\end{array}$ & $6-15$ & $5-14$ \\
\hline
\end{tabular}

Table (2): Shows characteristics of the studied patients. Regarding the age, more than two fifths (46.0\&40.0)of patients at Ain Shams and El Sayed Galal Hospitals had the age of $(20-<35 \mathrm{yrs})$. Considering the length of intubation and ventilation/days were ( 4-14 \& 3-15 respectively ). As regards length of stay in $\mathrm{CCU}$ were (6-15\& 5-14 respectively ).

Table (3):Presentation of studied nurses' knowledge about ventilator associated pneumonia (VAP) prevention bundle in pre/post tests

\begin{tabular}{|l|l|l|l|}
\hline \multirow{2}{*}{ Items } & \multicolumn{2}{l|}{ Studied nurses $(\mathrm{n}=70)$} \\
\cline { 2 - 4 } & Pre & \multicolumn{1}{|l|}{ Post } & Follow- up \\
\hline Definition of VAP & $42(60.0)$ & $57(81.4)$ & $65(92.9)$ \\
\hline Diagnostic measures & $34(48.6)$ & $61(87.1)$ & $64(91.4)$ \\
\hline Management of VAP & $38(54.3)$ & $58(82.9)$ & $63(90.0)$ \\
\hline Signs and symptoms of VAP & $44(62.9)$ & $56(80.0)$ & $63(90.0)$ \\
\hline Complications of VAP & $43(61.4)$ & $59(84.3)$ & $64(91.4)$ \\
\hline Definition of VAP prevention bundle & $30(42.9)$ & $58(82.9)$ & $62(88.6)$ \\
\hline Components of VAP prevention bundle & $32(45.7)$ & $56(80.0)$ & $61(87.1)$ \\
\hline $\bar{X}$ No \pm SD & $37.5 \pm 5.6$ & $57.8 \pm 1.7$ & $63.1 \pm 1.3$ \\
\hline T - value & T1 between pre \& posttests $=29.4^{*}$ \\
\cline { 2 - 4 } & T2 between post \& follow- up tests $=21.2^{*}$ \\
\hline
\end{tabular}

Table (3): Shows studied nurses' satisfactory knowledge about VAP prevention bundle in pre/posttests. Results indicated significant improvement in nurses' knowledge regarding post and follow - up assessment (mean $=57.8 \pm$
$1.7 \& 63.1 \pm 1.3$ respectively) compared to pre - assessment $(37.5 \pm 5.6)$, with $\mathrm{t} 1$ - test (between pre $\&$ post $)=29.4$ and t2 test (between post \& follow- up ) $21.2 \quad$ ), p $<0.05$. 
Minia Scientific Nursing Journal (Print) (ISSN 2537-012X) Vol. (3) No. (1) July 2018

Table (4): Presentation of studied nurses' knowledge about Risk factors of ventilator associated pneumonia (VAP) in $\mathrm{pre} / \mathrm{post}$ tests

\begin{tabular}{|c|c|c|c|}
\hline \multirow{2}{*}{ Items } & \multicolumn{3}{|c|}{ Studied nurses $(n=70)$} \\
\hline & Pre & Post & Follow- up \\
\hline \multicolumn{4}{|l|}{ Patients : } \\
\hline Disturbed level of consciousness & $41(58.6)$ & $55(78.6)$ & $60(85,4)$ \\
\hline Malnutrition & $13(18.6)$ & $52(74.3)$ & $56(80.0)$ \\
\hline Aspiration of contaminated secretion & $44(62.9)$ & $56(80.0)$ & $63(90.0)$ \\
\hline \multicolumn{4}{|l|}{ Nurses : } \\
\hline Suctioning frequently & $36(51.4)$ & $58(82.9)$ & $64(91.4)$ \\
\hline Utilizing clean gloves for tracheal suction & $29(41.4)$ & $57(81.4)$ & $63(90.0)$ \\
\hline Performing ineffective hand hygiene & $30(42.9)$ & $59(84.3)$ & $65(92.8)$ \\
\hline Rubbing with Alcohol when visible secretions & $9(12.8)$ & $55(78.6)$ & $59(84.3)$ \\
\hline Washing hands when there is no visible secretions & $35(50.0)$ & $56(80.0)$ & $62(88.5)$ \\
\hline \multicolumn{4}{|l|}{ Doctors : } \\
\hline Giving multiple antibiotics & $15(21.4)$ & $54(77.1)$ & $58(82.8)$ \\
\hline Giving broad spectrum antibiotics & $37(52.8)$ & $58(82.9)$ & $63(90.0)$ \\
\hline Intubating patients, nasally & $10(14.3)$ & $54(77.1)$ & $58(82.8)$ \\
\hline$\overline{\mathbf{X}}$ No $\pm \mathrm{SD}$ & $27.1 \pm 13.02$ & $55.8 \pm 2.08$ & $61.0 \pm 2.9$ \\
\hline \multirow[t]{2}{*}{$\mathrm{T}$ - value } & \multicolumn{3}{|c|}{ T1 between pre $\&$ post tests $=18.3^{*}$} \\
\hline & \multicolumn{3}{|c|}{ T2 between post $\&$ follow- up tests $=12.4^{*}$} \\
\hline
\end{tabular}

Table (4): Shows studied nurses' satisfactory knowledge about risk factors of VAP in pre/post tests. Results indicated significant improvement in nurses' knowledge regarding post and follow - up assessment (mean $=55.8 \pm$
$2.08 \& 61.0 \pm 2.9$ respectively) compared to pre - assessment $(27.1 \pm 13.02)$, with $\mathrm{t}-$ test $=18.3$ and 12.4 respectively), $\mathrm{p}<0.05$.

Table (5): Presentation of studied nurses' practices regarding care of patients with ventilator associated pneumonia (VAP) in pre/post tests

\begin{tabular}{|l|l|l|l|}
\hline \multirow{2}{*}{ Items } & Studied nurses $(\mathrm{n}=70)$ & \multicolumn{2}{l|}{} \\
\cline { 2 - 4 } & Pre & Post & Follow- up \\
\hline Infection control measures & $32(45.7)$ & $55(78.6)$ & $61(87.1)$ \\
\hline $\begin{array}{l}\text { Using sterilized ambo bag } \\
\text { neubelizer device }\end{array}$ & $29(41.4)$ & $56(80.0)$ & $62(88.5)$ \\
\hline Perform postural drainage & $34(48.6)$ & $58(82.9)$ & $64(91.4)$ \\
\hline $\begin{array}{l}\text { Perform percussion and vibration } \\
\text { technique }\end{array}$ & $33(47.1)$ & $55(78.6)$ & $63(90.0)$ \\
\hline Change patient's position frequently & $37(52.9)$ & $56(80.0)$ & $60(85.4)$ \\
\hline Endotracheal tube care feeding / care & $38(54.3)$ & $58(82.9)$ & $63(90.0)$ \\
\hline Nasogastric tube & $41(58.6)$ & $57(81.4)$ & $64(91.4)$ \\
\hline Ventilator care & $34(48.6)$ & $59(84.3)$ & $63(90.0)$ \\
\hline$\overline{\mathbf{X}}$ No \pm SD & $34.8 \pm 3.7$ & $56.7 \pm 1.5$ & $62.5 \pm 1.4$ \\
\hline T - value & T1 between pre \& post tests $=46.6^{*}$ \\
\cline { 2 - 4 } & T2 between post \& follow- up tests $=0.42 *$ \\
\hline
\end{tabular}

*Significant at $\mathrm{p}<0.05$

and follow - up assessment (mean $=56.7 \pm 1.5 \& 62.5 \pm 1.4$ respectively) compared to pre - assessment $(34.8 \pm 3.7)$, with $\mathrm{t}-$ test $=46.6$ and 0.42 respectively), $\mathrm{p}<0.05$.
Table (5): Reveals patients`satisfactory practices regarding care of patients with VAP in pre/post tests . Results showed significant improvement in patients' practices regarding post 
Minia Scientific Nursing Journal (Print) (ISSN 2537-012X) Vol. (3) No. (1) July 2018

Table (6): Presentation of studied nurses' practices regarding bundle prevention protocol of VAP in pre/post tests

\begin{tabular}{|l|l|l|l|}
\hline \multirow{2}{*}{ Items } & Studied nurses $(\mathrm{n}=70)$ & Follow- up \\
\cline { 2 - 4 } & Pre & Post & $63(90.0)$ \\
\hline Head elevation 30-45 degrees & $38(54.3)$ & $59(84.3)$ & $62(88.5)$ \\
\hline Mouth care with Chlorhexidine /8 hours & $33(47.1)$ & $56(80.0)$ & $64(91.4)$ \\
\hline End tracheal suctioning care & $39(55.7)$ & $57(81.4)$ & $63(90.0)$ \\
\hline Daily sedation vacation(break ) & $34(48.6)$ & $59(84.3)$ & $60(85.7)$ \\
\hline Assessment of readiness to extubate & $36(51.4)$ & $55(78.6)$ & $61(87.1)$ \\
\hline Administration of DVT prophylaxis & $37(52.8)$ & $56(80.0)$ & $62(88.5)$ \\
\hline Administration of PUD prophylaxis & $36(51.4)$ & $57(81.4)$ & $62.1 \pm 1.3$ \\
\hline $\bar{X}$ No \pm SD & $36.1 \pm 2.1$ & $57.0 \pm 1.5$ & \\
\hline \multirow{2}{*}{$\mathrm{T}-$ value } & T1 between pre \& post tests $=69.7 *$ \\
\cline { 2 - 4 } & T2 between post \& follow- up tests $=22.1 *$ \\
\hline
\end{tabular}

Table (6): Reveals patients` satisfactory practices regarding bundle prevention strategy of VAP in pre/post tests. Results showed significant improvement in patients' practices regarding post and follow - up assessment $($ mean $=$
$57.0 \pm 1.5 \& 62.1 \pm 1.3$ respectively) compared to pre assessment $(36.1 \pm 2.1)$, with $\mathrm{t}-$ test $=69.7$ and 22.1 respectively), $\mathrm{p}<0.05$.

Table (7): Presentation of anxiety level among the studied nurses in pre/post tests

\begin{tabular}{|l|l|l|l|}
\hline \multirow{3}{*}{ Anxiety Level } & \multicolumn{2}{|l|}{ Studied nurses } & \\
\cline { 2 - 4 } & Pre & Post & Follow - Up \\
\cline { 2 - 4 } & $\%$ & $\%$ & $\%$ \\
\hline Mild & 28.0 & 46.0 & 62.0 \\
\hline Moderate & 49.0 & 40.0 & 30.0 \\
\hline Sever & 23.0 & 14.0 & 8.0 \\
\hline
\end{tabular}

Table (7): Reveals studied nurses' anxiety level in pre/post tests. Concerning anxiety level, significant improvement was indicated in post test then follow - up test as regards anxiety severity ( $14.0 \& 8.0$ respectively ) compared by pre test 23.0 .

Table (8): Nurses` opinions regarding competency obstacles in caring of studied patients and suggested solutions ( pre test )

\begin{tabular}{|c|c|c|c|c|}
\hline \multirow[t]{2}{*}{ Items } & \multicolumn{2}{|c|}{$\begin{array}{l}\text { Ain Shams } \\
\text { Nurses }(n=40)\end{array}$} & \multicolumn{2}{|c|}{$\begin{array}{l}\text { El Sayed Galal } \\
\text { Nurses }(n=30)\end{array}$} \\
\hline & No & $\%$ & No & $\%$ \\
\hline \multicolumn{5}{|l|}{ Obstacles } \\
\hline Physical & 33 & 82.5 & 27 & 90.0 \\
\hline Psychological & 34 & 85.0 & 28 & 93.3 \\
\hline Administrative & 32 & 80.0 & 25 & 83.3 \\
\hline Social & 28 & 70.0 & 19 & 63.3 \\
\hline Mean No $\pm \mathrm{SD}$ & \multicolumn{2}{|c|}{$31.8 \pm 2.6$} & \multicolumn{2}{|c|}{$24.8 \pm 4.0$} \\
\hline$\%$ of Mean & \multicolumn{2}{|c|}{79.5} & \multicolumn{2}{|c|}{82.7} \\
\hline $\mathrm{T}$ test, $\mathrm{P}$ value & \multicolumn{4}{|c|}{$\mathrm{T}=8.3, \mathrm{P}<0.005$} \\
\hline \multicolumn{5}{|l|}{ Suggested solutions } \\
\hline Orientation program for newly nurses & 34 & 85.0 & 26 & 86.6 \\
\hline Enough supplies and sufficient technology & 37 & 92.5 & 28 & 93.3 \\
\hline Improve communication among health care team & 32 & 80.0 & 24 & 80.0 \\
\hline Inservice training & 32 & 80.0 & 25 & 83.3 \\
\hline Job description & 33 & 82.5 & 25 & 83.3 \\
\hline Psychological support for nurses and financial & 38 & 95.0 & 28 & 93.3 \\
\hline
\end{tabular}


Minia Scientific Nursing Journal (Print) (ISSN 2537-012X) Vol. (3) No. (1) July 2018

\begin{tabular}{|c|c|c|c|c|}
\hline \multirow[t]{2}{*}{ Items } & \multicolumn{2}{|c|}{$\begin{array}{l}\text { Ain Shams } \\
\text { Nurses }(n=40)\end{array}$} & \multicolumn{2}{|c|}{$\begin{array}{l}\text { El Sayed Galal } \\
\text { Nurses }(n=30)\end{array}$} \\
\hline & No & $\%$ & No & $\%$ \\
\hline \multicolumn{5}{|l|}{ inventiveness } \\
\hline Mean No \pm SD & \multicolumn{2}{|c|}{$34.3 \pm 2.6$} & \multicolumn{2}{|c|}{$26,0 \pm 1.7$} \\
\hline$\%$ of Mean & \multicolumn{2}{|c|}{85.7} & & 86.7 \\
\hline $\mathrm{T}$ test, $\mathrm{P}$ value & \multicolumn{4}{|c|}{$\mathrm{T}=16.1, \quad \mathrm{P}<0.001$} \\
\hline
\end{tabular}

Table (8): Presents nurses opinions about competency obstacles in care of studied patients and suggested solutions . Insignificant difference was found between Medical and Children Hospitals regarding the obstacles: physical, psychological, administrative and social. In relation to the suggested solutions, insignificant difference was observed regarding the suggested solution: orientation program, adequate supplies, relation among health care team, in service training, job description and nurses' support

Table (9): Incidence of ventilator associated pneumonia among studied patients in post tests

\begin{tabular}{|c|c|c|}
\hline \multirow{2}{*}{$\begin{array}{l}\text { Incidence of VAP at study } \\
\text { settings }\end{array}$} & \multicolumn{2}{|c|}{ Studied patients } \\
\hline & Post & Follow- up \\
\hline $\begin{array}{l}\text { Ain Shams Hospital } \\
(\mathrm{n}=20)\end{array}$ & $7(35.0)$ & $3(15.0)$ \\
\hline $\begin{array}{l}\text { El Sayed Galal Hospital } \\
\qquad(\mathrm{n}=20)\end{array}$ & $6(30.0)$ & $4(20.0)$ \\
\hline
\end{tabular}

Table (9): Shows incidence of VAP among studied patients at (Ain Shams University and El Sayed Galal Hospitals ) in post and follow up tests . Results showed significant reduction in follow - up assessment compared to post at Ain Shams University $=15.0 \& 35.0$ respectively and at El Sayed Galal $=20.0 \& 30.0$ respectively

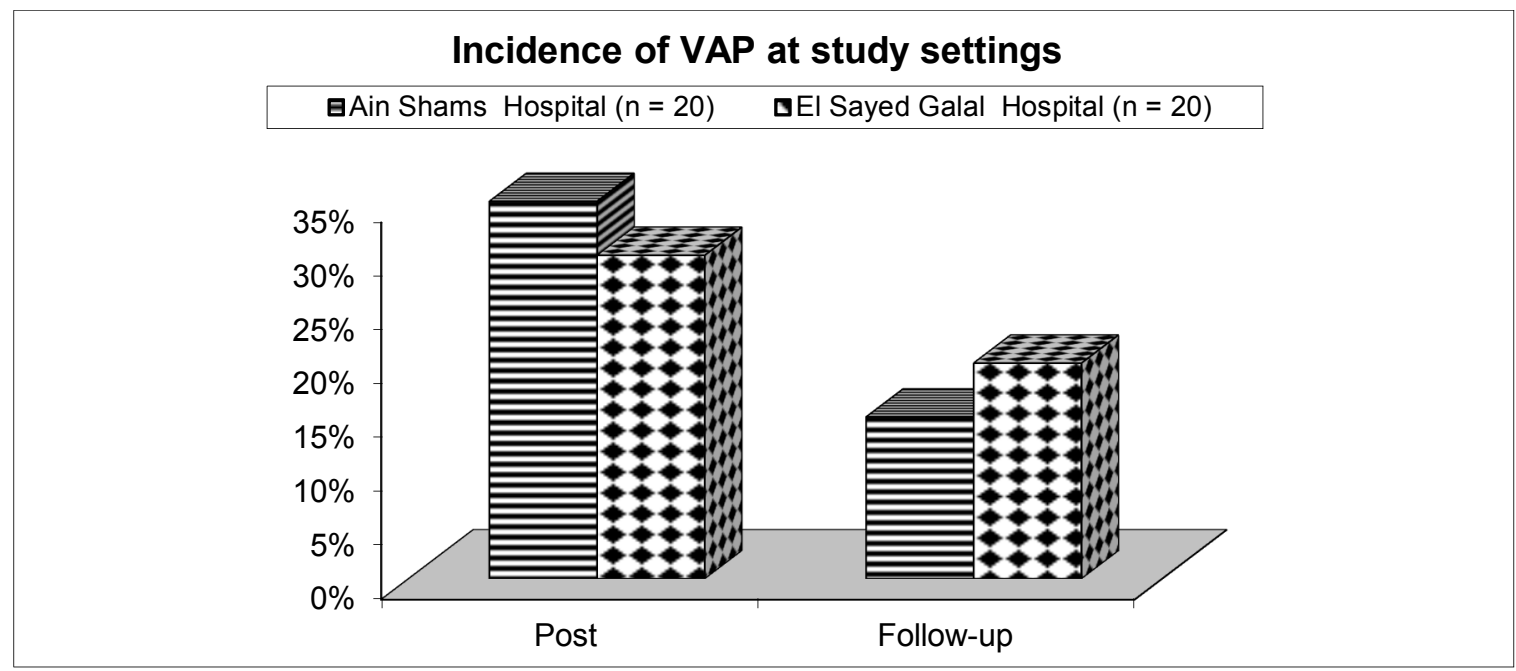

Figure (1): VAP among studied patients

\section{Discussion:}

Ventilator-associated pneumonia (VAP) is the leading cause of death among hospital-acquired infections and increases mortality, morbidity added to economic expenditure. The preventive measures include: staff education on bundle care, reduce colonization of aerodigestive tract and airway contamination . Ventilatory circuits changed when malfunctioning or visibly soiled. Heat and moisture exchangers changed every 48 hours or when become visibly soiled or mechanically malfunction . Anticoagulants is vital to avoid stress inflammatory response resulting in hyper-coagulation and minimal mobility . The ventilator bundle consists of a group of evidence-based practices that implemented together to dramatically reduce VAP incidence in mechanically ventilated patients (Russell et al. ,2016 \& Blot et al. ,2014) . The current study aimed to evaluate the effect of enhancing nurses ' competency on adherence to 
bundle prevention protocol for ventilator associated pneumonia (VAP)

In the present study as regards nurses , characteristics, more than half of them had the age of 25 $-<35$ yrs . This finding was supported by Elbokhary et al. (2015) \& Ibrahim (2014) who reported that the mean age of the studied nurses was $(32.32 \pm 6.70)$ with age ranged 20-40 years. In the same context, regarding the gender , female were represent a majority of the sample. This may be due to the greater fraction of the nurses in Egypt was female and may also related to the studying of nursing in Egyptian universities were exclusive for females only till few years ago . Badawy (2014) mentioned that more than half of the studied subjects were females .

Considering the educational level, more than half of studied nurses had diploma nursing This result may be due to shortage of nurses' number that didn't let them have time to attend courses, unavailable supervision to follow it and shortage of nurse with high qualification, lack of motivation to attend to training courses . Kalanuria et al. (2014) \& Ali (2013) reported that the majority of the nurses in the study group were diploma holders. In relation to previous training, more than one third of them had previous training.

As regards studied nurses' satisfactory knowledge about bundle prevention protocol for ventilator associated pneumonia (VAP). Results showed significant improvement in post test compared to pre test . This result may be interpreted as education has a vital role in improving nurses' knowledge and practices, then consequently patients' outcomes. The inadequacy of nurses' knowledge might be as a result of absence of continuous educational program . The previous findings were supported by Rashed \& Emam (2015) who reported that less than half of studied nurses had unsatisfactory knowledge about VAP . Shaban et al. (2015) stated that, nurses should have adequate information about care of patients with VAP ( definition , diagnosis , characteristics, risk factors, treatment and complications ) to decrease VAP rate in critical care units . . Dewit et al. (2016) emphasized that nurses` orientation needs to include VAP prevention bundle and a chance to work with the equipment and patients prior to being on the unit . Shaban et al. (2016) reported that $(69.7 \%)$ the nurses had average knowledge about VAP and care bundle

In addition, Al - Ashry \& Modrykamien (2014) reported that studied sample should have correct knowledge regarding methods of infection control, suction, routine oral care, enteral feeding, sterilizing instruments and devices related to respiratory tract . Ali (2013) recognized that $54.9 \%$ of nurses agreed with peptic ulcer prophylaxis that plays a role in preventing lung infections and $26.8 \%$ of nurses said that deep venous thrombosis prophylaxis has no role in preventing lung infections . Elbokhary et al. (2015) \& Sabzevari et al. (2015) cleared that frequent change in suction systems , semi-recumbent position and kinetic beds decrease pneumonia risk and occurrence. Moreover, cuff pressure should be maintained above $20 \mathrm{~cm} \mathrm{H} 2 \mathrm{O}$ to prevent the aspiration and below $30 \mathrm{~cm} \quad \mathrm{H} 2 \mathrm{O}$ to prevent tracheal mucosa injury .
Concerning ventilator associated pneumonia prevention bundle, results indicated significant improvement in nurses' knowledge regarding post and follow - up assessment. This finding may be due to absence of VAP bundle protocol, periodically follow up for nursing staff and training courses. Ismail \& Zahran (2015) reported that more than three fourth of nurses had high knowledge regarding components of bundle prevention in ventilator associated pneumonia. In Kollef et al. (2014) 39.1\% of nurses reported that the humidifier type should have both heat and humidity exchangers . In addition, kinetic standard beds reduce the risk of VAP as known by $58.4 \%$ of the participants.

In relation to studied nurses' satisfactory practices as regards bundle prevention protocol for ventilator associated pneumonia (VAP) . Results showed significant improvement in post test compared to pre test . This finding may be due to studied nurses years of experience in intensive care unit and majority of them were diploma holders,so need more VAP bundle protocol, practical training courses and more audit from ICU supervision. Mohamed (2014) found that less than half of nurses under study had adequate practices on : hand Washing, performing postural drainage, percussion and vibration, suction, oral care for, endotracheal tube care, nasogastric tube feeding, change position and ventilator care for patients with VAP

Moreover, Malombe (2015) \& Alsadat et al. (2012) reported that $76.6 \%$ of nurses have fair practice level of suction technique . In addition, some interventions had very high percentages: elevated head of bed between $30-45^{\circ}(92.7 \%)$, oral care to $(95.1 \%)$, or mobilization $(86.6 \%)$, spontaneous breathing trials $(72 \%)$, maintain cuff pressures on endo tracheal tube . Shaban et al. (2016) \& Thille et al. (2013) illustrated that most nurses did not implement infection control measures when applying tracheal suctioning or dealing with suction equipment and absence of correct oral care protocol in the ICUs, added to oral care is carried out without the use of tooth brushing or antiseptic solutions .

Concerning anxiety level , significant improvement was indicated in post test then follow - up test as regards anxiety severity compared by pre test . Dewit et al. (2016) stated that, intensive care unit is one of the most stressful environments for its staff. These stresses have negative effects on the mental health and performance of the nurses and physicians. The urgency needed, caring for the dying, lack of equipment and facilities, and not communicating well with other colleagues are all stressful for nurses and doctors. This stress is tangible in intensive care and internal units. These environments can be potentially stressful and require stressrelated interventions .

Regarding competency obstacles, insignificant difference was found between the two study settings . Safdar et al. (2015) \& Bucher et al. (2014) were in agreement with the previous result and reported that, critical care nurses experience a variety of competency obstacles in their work environment, which are the factors that hinder intensive care nurses' capacity to perform their jobs and that are associated closely with their immediate work environment: working in a closed place for long periods, death, higher level of decision making, workload and 
understaffing are mentioned reasons for nurses job dissatisfaction . In addition, Wong et al. (2016) \& Lewis et al. (2014) stated that lack of job description, bias of administrators, poor work organization, inadequate policies, procedures and staff training, non nursing duties and inconstant availability of medical staff, appreciation of good performance and administrators fairness were represent competency obstacles in the critical care unit

\section{Conclusion:}

In the light of the present study, it can be concluded that, enhancing nurses' competency (knowledge and practices) through educational guidelines was helpful on adherence to bundle prevention protocol for ventilator associated pneumonia (VAP), whereas significant improvement was indicated in post test compared to pre . Moreover , patients' health condition assessment (incidence of VAP ) was reduced in follow-up test .

\section{Recommendations:}

Based on results of the current study, the following recommendations can be deduced:

- Application of training program to other settings is to be taken into consideration.

- The study reinforces the need for sustained education and training regarding VAP prevention bundle.

- An orientation program for the newly assigned nurses in the critical care units.

- Assess the long term effects of such guidelines on critically ill patients quality of life.

- Further studies should be carried out on a large number of critical care nurses with evidence of results and generalization

\section{References}

[1]. Al Ashry, H. \& Modrykamien, A. (2014): humidification during mechanical ventilation in the adult patient. BioMed Respiratory Journal, 1(2): 33-7.

[2]. Ali, N. (2013): Critical Care Nurses' Knowledge and Compliance with Ventilator Associated Pneumonia Bundle at Cairo University Hospitals. Journal of Education and Practice,4(15), 67- 9 .

[3]. Alsadat , S. , Mazloum, A., Eltayeb, S., Dakkak, M. , Esber, N. \& Kherallah, B. (2012): Use of ventilator associated pneumonia bundle and statistical process control chart to decrease VAP rate in Syria . Avicenna Journal of Medicine , Oct,2(4):79-83 .

[4]. Badawy, A. (2014): A study of impact of a structured teaching program for prevention of ventilator associated pneumonia on knowledge and practice of intensive care nurses at central quwesna hospital, Egypt. Med. Journal Cairo Univ.,82(1): 803-13.
[5]. Blot, S., Poelaert, J. \& Kollef, M. (2014) : How to avoid microaspiration? A key element for the prevention of ventilator-associated pneumonia in intubated ICU patients. BMC Infect Dis , 14:11923 .

[6]. Bucher, L., Dirksen, S., Heitkemper, M. \& Lewis, S. (2014): Medical-Sugical Nursing Assessment and Managment of Clinical Problems, 9th ed. , USA: Mosby, 316-60.

[7]. Dewit, S., Stromberg, H. \& Dallred, C. (2016): Medical-surgical nursing: concepts and practice. Elsevier Health Sciences: 694-7.

[8]. Elbokhary, R., Osama, A. \& AL-khader, M. (2015): Knowledge and practice of ICU nurses regarding endotracheal suctioning for mechanically ventilated patients in khartoum teaching hospital. Intensive care Journal, 2(4): 97- 102 .

[9]. Fathy, A., Abd Elhafeez, R., El-gilany, A. \& Abd Elhafez,S. (2013): Analysis of ventilator associated pneumonia (VAP) studies in Egyptian university hospitals Egyptian Journal of Chest Diseases and Tuberculosis, 2(16) : 17-25.

[10]. Hinkle, J. \& Cheever, K.(2014): Textbook of Medical-Surgical Nursing, 13th ed. , Philadelphia: wolters kluwer health, 1389-400.

[11]. Ibrahim, A. (2014): Impact of a structured teaching program for prevention of ventilator associated pneumonia on knowledge and practices of intensive care nurses at central quwesna hospital, Egypt, Med. Journal of Cairo University., 82 (1): 8 - 11.

[12]. Ismail, R. \& Zahran, E. (2015) : The effect of nurses training on ventilator-associated pneumonia (VAP) prevention bundle on VAP incidence rate at a critical care unit , Journal of Nursing Education and Practice , 5(12): 42-8.

[13]. Kalanuria , A., Zai , W. \& Mirski , M. (2014): Ventilator-associated pneumonia in the ICU. Crit Care ,18(2):208 - 12 .

[14]. Kollef, M.,Chastre,A. \& Fagon,M. (2014): Prevention of hospital associated pneumonia and ventilator associated pneumonia. Critical Care Med. Journal,5(2): $60-5$

[15]. Larrow, D. (2016): Ventilator associated pneumonia in ICU. Journal of Critical Care Nursing, 20(3) : 100, 10 .

[16]. Lewis, L., Dirksen, R., Kemper, M. \& Bucher, L. (2014): Medical-surgical nursing: Assessment and management of clinical problems, 9th ed. , Missouri: Mosby .

[17]. Malombe, P. (2015): Evaluation of nurses' knowledge and prevention practices of ventilator associated morbidities in critical care unit, kenyatta national hospital. Critical Care Journal, 22(10): 428 . 
[18]. Marini , A.\& Khan , R. (2016): Multifaceted bundle interventions shown effective in reducing VAP rates in our multidisciplinary ICUs. BMJ Open Quality,5(1):43-9.

[19]. Michetti, C., Fakhry, S., Ferguson, P., Cook, A., Moore, F. \& Gross, R. (2014): "Ventilatorassociated pneumonia rates at major trauma centers compared with a national benchmark: a multiinstitutional study of the AAST.". Journal of Trauma and Acute Care Surgery, 72(5): 1165-73.

[20]. Mohamed , K. (2014): Compliance with VAP bundle implementation and its effectiveness on surgical and medical sub-population in adult ICU . Egyptian Journal of Chest Diseases and Tuberculosis . 63(1): 9-14.

[21]. Mori, H., Hirasawa, H., Oda, S., Shiga, H., Matsuda, K. \& Nakamura, M. (2016): Oral care reduces incidence of ventilator-associated pneumonia in ICU populations. Intensive Care Medicine Journal, 230- 6 .

[22]. Rashad, I. \& Emam, Z. (2015): Prevention of ventilator associated pneumonia. JNEP. J., 5(12): 41- 5 .

[23]. Russell , C., Shiroishi , M., Siantz , E. , Wu , B. \& Patino , C. (2016): The use of inhaled antibiotic therapy in the treatment of ventilator-associated pneumonia and tracheobronchitis: A systematic review. BMC Pulm Med ,16:40 - 6 .

[24]. Sabzevari , s., Mirzaei, T., Bagherian , B. \& Iranpour , M. (2015) : Critical Care Nurses' Attitudes about Influences of Technology on Nursing Care . British Journal of Medicine \& Medical Research , 9(8): 1-10.

[25]. Safdar, N., Dezfulian, C., Collard, H. \& Saint, S. (2015): Clinical and economic consequences of ventilator-associated pneumonia: a systematic review. Critical Care J., 33(10): 2184-93.

[26]. Shaban, Z., Alaa El-Din, S., Attia, N. \& Akab, M. (2015): Efficacy of Implementing Nursing Care Protocol on the Incidence of Ventilator Associated Pneumonia in Intensive Care Unit at Tanta Emergency Hospital, J Am Sci, 12(2):40-52 .

[27]. Thille, A., Richard, J. \& Brochard, L. (2013): The decision to extubate in the Intensive Care Unit. J. of Respir. Crit. Care Med., 187(53): 1294-1302 .

[28]. Wong, T., Schlichting , A., Stoltze, A., Fuller , B., Peacock , A. ( 2016): No decrease in early ventilator-associated pneumonia after early use of chlorhexidine . Am J Crit Care , 25(2):173-7.

[29]. Zack, J., Garrison, T. \& Trovillion, E. (2012): Effect of an education program aimed at reducing the occurrence of ventilator associated pneumonia. Critical Care Med. J., 30(12): 2407-12. 